\title{
Crítica literaria en el Chile neoliberal: la invisibilización de la disidencia.
}

\section{Resumen}

Este artículo aborda el ejercicio de la crítica literaria en Chile al interior de las, cada vez más, complejas prácticas de anulación de la disidencia. La negación de la diferencia que atrapa a la sociedad chilena, suprime las disonancias, eludiendo la diversidad discursiva. Por lo mismo, el mercado convierte a la crítica literaria en un eslabón más de la cadena de difusión del libro, una parte de la estrategia de propaganda. La crisis que vive la crítica literaria y nuestra literatura es solo una parte de la catástrofe cultural que implica la mercantilización de la realidad en su conjunto. Asistimos a una privatización del pensamiento crítico y, por ende, a la neutralización de las subjetividades; es por ello que sostengo la urgencia de reivindicar la crítica desde el minoritario territorio de la subjetividad como un acto de resistencia cultural.

Palabras claves

crítica literaria, crítica literaria chilena, neoliberalismo en Chile, política, crítica académica, medios de comunicación masivos.

\begin{abstract}
This article addresses the exercise of literary criticism in Chile in the context of the increasingly complex practices of denial of dissent. The non-acceptance of difference that entraps the Chilean society eliminates the discordances by avoiding discourse diversity. The market, then, turns literary criticism into one more link of a book's distribution channels and into a component of the advertising campaign. The crisis that literary criticism and our literature are going through represents only a fraction of the cultural catastrophe brought about by the commercialization of reality as a whole. We are now witnessing a privatization of critical thinking and, consequently, a neutralization of subjectivities; I therefore maintain how urgent it is to, from the reduced territory of subjectivity, vindicate criticism as an act of cultural resistance.

Keywords


La crítica literaria es un modo particular de lectura en donde un/una sujeto lector describe, analiza y evalúa una o varias obras literarias. La prevalencia de alguna de estas tres funciones hará posible la subdivisión interna de la crítica literaria. Privilegiar la función descriptiva y analítica, más el uso de un aparataje conceptual explícito, nos sitúa en lo que se denomina crítica literaria académica. En cambio, si es el análisis/evaluación lo que adquiere protagonismo, la crítica será considerada periodística. En la crítica académica la evaluación acontece, generalmente, al momento de la elección del objeto: él/la crítico propone la lectura de un objeto que considera valioso o de alguna forma importante, ya sea por su singularidad o porque forma parte de alguna estructura mayor o corriente que también se hace necesario describir y analizar, para ir generando un tipo de conocimiento que vaya más allá de la obra en particular. En la crítica en prensa, por su parte, se presta especial atención a la obra particular, aunque claramente existen intentos de agrupación de obras y de identificación de estructuras aglutinantes.

La crítica literaria, entonces, modula sus diferencias internas a partir de diversas intensidades o focos de interés. La extendida intención de diferenciar los tipos de crítica literaria a partir del lenguaje utilizado resulta inútil, en tanto el lenguaje de la crítica literaria siempre es especializado. Si el lenguaje es más o menos comprensible por públicos más o menos extensos, corresponde a un fenómeno que tiene que ver más bien con definiciones de segmentación sistémica del conocimiento, división de los lectores, jerarquización entre especialistas y legos. Estos recortes afectan en general a todas las críticas (de cine, de teatro, música, etc.) e incluso a otros tipos de saberes, como el científico por ejemplo, y no particularizan a la crítica literaria. También es inútil la pretensión de mayor verdad asignable a una $\mathrm{u}$ otra crítica. Al ser modulaciones de intensidades diferentes, ninguna de por sí puede arrogarse superioridad alguna, a menos que se plantee que siempre es más cercano a la verdad describir/analizar que analizar/evaluar. Lo que sí está claro es que en ambas modulaciones hay 
posicionamientos tácticos y estratégicos que van desde aspectos específicos de una obra en particular hasta lo que se supone qué es y para qué sirve la crítica literaria $y$, por fin, la propia literatura.

He planteado lo anterior, para abrir un espacio a una serie de posicionamientos que me parece necesario realizar en la actual contingencia de la crítica literaria que, en apariencia, considerando solo la cantidad de publicaciones críticas, parece no estar atravesando un momento especialmente decadente o por lo menos no más o menos decadente que la propia creación literaria. A lo que sí debemos prestar atención es a las mutaciones de la crítica literaria en el presente escenario. Para ello debemos tomar distancia de dos actitudes igualmente conservadoras. Más bien dicho dos delirios, extremadamente seductores: la fantasía de la catástrofe, que ya ocurrió o que está a punto de ocurrir, y la fantasía del presente como el mejor momento. Ambas ficciones se igualan, porque son parte de un pensamiento mítico donde lo más importante parece ser que el enunciante de la catástrofe o de la celebración del presente como edad de oro, logre decirle al mundo que él, y sólo él, se ubica en un lugar privilegiado para detectar la catástrofe o el esplendor. En ambos delirios, el sujeto enunciante se siente liberado de la maraña del tiempo, de la mediocridad de lo cotidiano, de lo habitual y sus requerimientos básicos, comunes, vulgares. En cualquiera de esos delirios, el sujeto puede vivenciar una suerte de experiencia aristocrática, situándose fuera de la esclavitud del tiempo que corre para todos los mortales.

La proliferación de enunciaciones que remarcan el carácter autoidentitario de distinción que otorga el acto de leer, se encuentra relacionada en la actualidad con la emergencia de una suerte de microcrítica, cuyo soporte está en las redes sociales virtuales y en la que su característica principal es la reducción al mínimo del análisis e incluso su eliminación total para dejar únicamente la evaluación como principal objetivo de la crítica literaria. En términos abstractos no cabría más que celebrar el auge de esta microcrítica, ya que amplía de manera evidente el ejercicio de la crítica literaria, sumando una multiplicidad de voces y puntos de vista hasta hace algún tiempo invisivilizados. Así la microcrítica tendería a la 
desjerarquización del territorio crítico, restando preeminencia a los focos tradicionales, disputando con ellos la capacidad de sancionar un canon y delimitar tendencias. La microcrítica ayudaría a la necesaria fragmentación del espacio crítico literario, impidiendo que se establezcan poderes absolutos; la microcrítica, desde este enfoque, podría ser vista como un paso importante en la democratización del ejercicio de la crítica literaria, horizontalizando un espacio hasta hace poco marcado por una feroz verticalización, claramente autoritaria.

Sin embargo, no hay tal diversidad, y al igual que buena parte de los primeros sueños relativos al uso de internet, la realidad ha dictaminado otra cosa. En el tema que nos convoca, la proliferación de microcríticas y voces atentas al devenir de la literatura no marca necesariamente un camino hacia la diversidad ${ }^{1}$. Lo anterior, se relaciona con la profundización de un uso específico que las sociedades contemporáneas asignan a la literatura: la experiencia literaria se inclina a convertirse en una modulación sofisticada del exhibicionismo de una elite o una parte más de la industria de la entretención masiva. Su síntoma mayor es la prevalencia de la práctica acumulativa de información por sobre la práctica de la lectura. Cada día surgen más lectores voraces, aquellos que han alcanzado un nivel de consumo de obras literarias tan elevado que serían merecedores de una medalla olímpica. Esta sospechosa compulsión lectora, siempre va acompañada de un frenesí de acumulación de todo tipo de información sobre títulos, nombres de autores, vidas de autores, nombres de editoriales, de editores, de diseñadores, de pequeñas y secretas librerías, y futuros lanzamientos. El lector tipo de la literatura del siglo XXI se fue a vivir al mall y está continuamente renovando su stock; una buena parte de estos consumidores, se instaló en el distrito del lujo y se siente cómodo allí, aunque declara cínicamente su desagrado, su malestar y su autonomía respecto a la industria de la entretención. Respecto al autor de la microcrítica, cabe destacar que se relaciona directamente con los autores y editoriales, manifestando su entusiasmo por la nueva publicación.

\footnotetext{
${ }^{1}$ Al respecto, véase también el ejercicio de los booktubers, una práctica que se creyó novedosa y que rápidamente demostró ser nada más una estrategia publicitaria dirigida a un público juvenil.
} 
Práctica, en todo caso, compartida con académicos y críticos de prensa que se comunican a través de redes sociales, con autores y editoriales para informarles que han hablado positivamente de tal o cual libro. La ética de la microcrítica es la ética de la pertenencia a una elite en la que el valor exhibitivo es esencial. El resultado es el adelgazamiento de la crítica hasta el punto del eslogan, porque no hay análisis, no hay método, no hay coherencia más que la sustentada por el gusto, la moda, la pose o la que dicta la palabra cómplice que asegura la pertenencia desesperada al grupo privilegiado, por lo general ligado a las directrices del mercado.

Por lo mismo, el mercado convierte a la crítica literaria en un eslabón más de la cadena de difusión del libro, una parte de la estrategia de propaganda. Aquello que hace algunos años se veía como una suerte de amenaza, hoy se vivencia como una invitación a participar que ha sido aceptada por buena parte de los consumidores de productos literarios. Lo que se espera es que la circulación del producto libro no sea afectada hasta llegar al consumidor final y ese consumidor, a su vez, no debe ver interferida su experiencia de lectura. En realidad tal sujeto no es un lector, es parte del público consumidor, una pieza de la audiencia cautivada por distintas estrategias, las cuales van desde las más amplias y burdas hasta las más pequeñas y sofisticadas. El sujeto lector ha pasado a ser un consumidor que busca, por sobre todo, autoafirmar y validar su nicho específico de lecturas, por lo que evidentemente no requiere de la crítica. La consolidación de nichos de lectores permite que el mercado se fragmente y, con ello, que los diversos espacios alcancen cierta autonomía relativa. Evidentemente estos nichos de consumo literario estarán cada vez más inmunizados frente a la crítica que no respete el ethos que le da forma a su identidad como grupo. Para el mercado del libro y para sus consumidores, la crítica debería dedicarse a la etiquetación, resumiendo el libro y dando cuenta de sus componentes, al modo de un producto ofrecido en un supermercado.

Entonces, las reflexiones sobre la crítica literaria deben pasar necesariamente por interrogarse por los usos que la actual contingencia asigna a la 
literatura. Desde esta perspectiva, la crítica literaria siempre está afirmando qué cree respecto de la literatura, por lo menos en tres niveles: si opta por considerarla parte de la industria de la entretención, es decir, la literatura diluyéndose en la banalidad del espectáculo, o bien, la literatura como modulación específica de acumulación de símbolos de estatus, o sea práctica del lujo $\mathrm{y}$, por último, la literatura como una práctica escritural estético-política. Las dos primeras posturas, plantean su complicidad en el terreno del consumo, de la mercancía y su imparable frenesí acumulativo. En ambas la banalidad es la marca distintiva, ya que permite la actividad acumulativa, por medio de la indiferenciación y aplanamiento de los significados. Y si bien ambas son acumulativas, la literatura como actividad lujosa que permite diferenciar a los bárbaros de los sofisticados, se caracteriza por una marcada estetización, que podríamos entender como un fetichismo de la imagen, es decir, los productos literarios valen en cuanto "yo" los descubro, "yo" los poseo, "yo" los uso, "yo" los exhibo.

Para romper este esquema de consumo literario se hace necesario llevar la reflexión más allá del campo específico de la crítica literaria y pensar críticamente en la distribución y jerarquización de los saberes y la creación de espacios culturales autosuficientes.

La ausencia de crítica es la ausencia de disenso, de igual modo, el rechazo a los discursos críticos es la negación del disenso. Una sociedad que pretende la desaparición del disenso, es una sociedad que ha establecido como hegemonía la unidad de un diseño que no puede ser modificado. Se instala así, una verdad, una representación de lo real incapaz de aceptar la diversidad y, por lo mismo, la caída de las autonomías. El arte, en nuestro país, en cualquiera de sus manifestaciones, es asumido desde su autonomía. Esto implica la segmentación del campo cultural en esferas independientes e incapaces de retroalimentarse. Tal es así que el cine o la literatura o el teatro, por nombrar solo algunos regímenes artísticos, conviven sin diálogo, sin vasos comunicantes entre sí. Esta fragmentación impide la generación de una comunidad de las artes y el diálogo entre las diversas producciones artísticas y, lo más importante, con la sociedad en su conjunto. 

Crític a literaria en el Chile neoliberal: la in visibilización de la disidencia.

Debemos recordar que buena parte de la instalación absolutista de las lógicas de mercado en la sociedad chilena, dependieron de una estricta partición de los saberes. Así durante décadas, desde la dictadura hasta los sucesivos gobiernos democráticos, el dogma de que la economía era una esfera autónoma de conocimiento manejada por expertos en macroeconomía permitió que el neoliberalismo avanzara hasta teñir con sus lógicas hasta las prácticas más mínimas del cuerpo social. Cualquier intento de torcer el funcionamiento de las políticas económicas hacia la resolución de problemas urgentes, fue considerado como populista, es decir un conocimiento menor, no científico, más bien político. Había que mantener a cualquier precio la estabilidad del diseño económico.

Al interior de estas lógicas neoliberales, la literatura solo puede tener dos destinos posibles, a saber: como actividad privada y como actividad masiva. Nunca, en ningún caso como actividad pública. Quienquiera que crea que las ferias de libros y demás encuentros literarios masivos son actividades que tienen que ver con la construcción de un espacio público, se equivoca. La masividad es lo opuesto a lo público, porque se ubica en el terreno del espectáculo que siempre redundará en la reiteración de lo mismo, ya que no pone en duda ningún diseño, ninguna jerarquía, ninguna partición ya establecida.

Pues bien, la crítica acontece en el terreno de lo público; es más, ayuda a crear el espacio público, entre otras razones porque permite la visibilización de lo oculto $\mathrm{u}$ accesible a las elites. Pero entendamos que visibilizar es más complejo que promocionar un libro para que sea adquirido por los consumidores. Visibilizar es poner en conflicto jerarquías y particiones establecidas. Así, si esta función solo es asumida por productores pertenecientes a la micro, pequeña o gran industria del libro, y a los grupos de consumidores de éstos, volvemos a caer en la lógica del consumo de una mercancía. Tal parece ser hoy la lógica que domina el mundo literario. Esto significa, nada más y nada menos, que la invisibilización de la escritura. Por tanto, todo texto crítico, generado sin la intervención del autor o la editorial y sin la complicidad del grupo consumidor, sea de elite o masivo, se constituye en una amenaza que habría que eliminar. La eliminación del crítico y el 
exterminio de la crítica, se constituye entonces como meta o expectativa central para la estabilidad económica editorial y biográfica del autor. El régimen literario, por tanto, opera del mismo modo en que se ejerce la política nacional, invisibilizando el discurso crítico.

Respecto a la crítica literaria académica, quiero hacer dos precisiones. En primer lugar, no hay una Academia, sino diversas academias. Lo segundo, se refiere a un permanente juicio que acusa a los estudios literarios científicos de usar metalenguaje, canonizar y estar concentrados en producciones literarias no contingentes. Esta burda caracterización o estereotipo noventero, favorablemente ha quedado atrás. La crítica académica no está ni cerca de canonizar con la fuerza que lo hace el mercado y los grupos de consumidores. Los estudios literarios se han vuelto interdisciplinarios, es decir, culturalistas; el exceso de metalenguaje, no es ya la principal característica de este tipo de crítica y, además, la investigación universitaria de hoy en día, se enfoca en una diversidad de producciones literarias, en tanto géneros, contingencia y lugares ligados al margen: género, provincia, libros de bajo tiraje. Esa continua e ingenua crítica a la crítica producida en las distintas academias, solo reproduce la segmentación de saberes y desliza el foco, porque deja al mercado incólume, además de tachar todo el conocimiento ahí acumulado como inútil y fácilmente descartable.

Desde mi perspectiva, el hacer crítico literario, se orienta a identificar el diseño de lo real que se expresa en una formulación escritural específica, la literatura, rastreando en sus hablas, lugares, jerarquías, procesos de subjetivación, leyes del género y subversiones a tales leyes, las cercanías y distancias en torno a las hegemonías de la sociedad, la cultura y la política. Desgraciadamente, hay un férreo control de la crítica literaria con la finalidad de restringir la diversidad de hablas de quienes la practican, porque Latinoamérica, nuestro país, sigue siendo el lugar donde lo visible (la crítica visible) proviene de las elites y de quienes se cuelgan de las elites. Además, es necesario considerar que el campo literario nacional, reproduce las tramas de posicionamientos sociales. Por lo mismo, el ejercicio de una crítica que se manifieste disidente a pertenecer a camarillas, 
tribus, "carteles", grupos informales de sujetos con alta presencia mediática, orientados a posicionar las producciones literarias de los miembros de tal elite, se ve constantemente sometida a estrategias de violencia invisibilizadora. El objetivo es, en última instancia, la eliminación de las hablas del disenso, del desacuerdo, no complacientes con la hegemonía del mercado y las tramas de poder.

Aun así, en el contexto del obligatorio y generalizado repliegue de los discursos críticos, pasando por la redefinición de los espacios de legitimación de las obras literarias, llegando hasta la propia figura del crítico literario, la crítica literaria se niega a decretar su defunción. Aunque esto no es precisamente auspicioso, ya que ha tenido un alto costo. Esto ocurre por la enorme capacidad de adaptación del crítico literario, un agente constituido por una subjetivación líquida, que le permite adecuarse con naturalidad a un campo donde las reglas están impuestas por la lógica de mercado. Es así como se ha radicalizado la presencia de un sujeto que resume el libro y aplica en su evaluación el criterio del gusto, del sentido común, generalmente positivo, respecto al artefacto literario. Lo anterior implica la negación de toda politicidad del texto literario tanto en su metatextualidad como en cualquier vínculo con la realidad y la historia. Se elude, a fin de cuentas, la problematización de la literatura.

Es un lugar común, emitido especialmente por los críticos profesionales, señalar que la crítica literaria no le importa a nadie. Pero este juicio es errado, no es que no le importe a nadie, sino que la crítica literaria está amenazada por la insignificancia, al igual que todos los discursos críticos que se circunscriben a la lógica descriptiva-evaluativa de un determinado producto. Así, tanto la literatura como la crítica son reducidas a unos pocos significados estandarizados o, más bien dicho, la crítica se visibiliza funcionando como una suerte de generadora de descriptores, por lo general legitimadores, positivos, de una determinada producción literaria.

El juicio decadentista ante este panorama nos lleva a asumir una derrota cultural que no por ser constatada debe implicar la cosificación de las discursividades ni la desaparición del género crítico. Asumiendo la derrota, es 
posible generar un proyecto de cambio. Ese proyecto de cambio pasa obligatoriamente por la necesidad de convertir el texto crítico en una instancia de politización, es decir, siguiendo a Rancière, de intento de redistribución de lo dado, de aquello que está sancionado como un orden establecido. Solo la politización puede oponerse al aplanamiento y a la insignificancia subsecuente.

Ahora bien, la politización requiere de una nueva autocomprensión del rol de la subjetivización crítica. La posición de sujeto tiene un carácter discursivo, tal como señala Laclau y Mouffe en Hegemonía y estrategia socialista: "las diferentes posiciones subjetivas son el resultado de articulaciones constituidas por medio de una operación hegemónica" (En Peller 54). Lo cual según Mariela Peller:

[...] significa que las posiciones de sujeto no están determinadas con anterioridad a la articulación discursiva que las constituye como tales. Las posiciones de sujeto no estarían constituidas con antelación al proceso de significación en el cual se inscriben y emergen, sino que son posiciones construidas discursivamente en ese proceso de articulación hegemónica. (54)

Por lo mismo, será necesario considerar que el sujeto crítico se articula en su discursividad y se construye discursivamente a través de la articulación hegemónica. Por tanto la discursividad crítica no opera en un fuera de la hegemonía, un fuera que obviamente no existe, sino más bien en la posibilidad de operar en la crisis de la discursividad hegemónica. Este accionar implica, por tanto, que la crítica literaria, aunque subsumida en las lógicas de poder, puede intentar una rearticulación de la práctica crítica. De acuerdo a Judith Butler:

La acción sólo es posible como una práctica reiterativa y rearticuladora, inmanente al poder. Lo nuevo podrá emerger en una repetición de la 
norma que no sea su refuerzo sino su desplazamiento. Si bien la reiteración constante de la norma [...] abre el espacio a la posibilidad de un cambio por medio de la acción política, siempre existe el riesgo de que esa identidad se constituya como un instrumento del mismo poder al que intenta oponerse. (En Peller 64)

¿Cómo, entonces, en el campo de la crítica literaria (en prensa, en la academia) entender el acto de interrupción de la reiteración maniática de la norma? Creo, en este punto, que en los tiempos que corren son varios los desplazamientos necesarios y urgentes: el primero, tiene que ver con la elección del objeto a criticar. Podría parecer menor, pero en este simple gesto toda una geopolítica de la circulación de los discursos se encuentra convocada. El primer gesto ético, político, de la crítica literaria pasa por la elección del objeto. Aquí están implicadas cuestiones no solo comerciales, las transnacionales versus las editoriales independientes, sino también nacionales, centralismo versus regionalismo y, por nombrar solo una más, la posibilidad de pertenencia del sujeto crítico a una de las tantas cofradías o camarillas que limitan su elección. Así, para el sujeto crítico estandarizado existen una enorme cantidad de fenómenos con los que simplemente no va a interactuar jamás, porque ya en el acto de enfocar algunos objetos se produce un desplazamiento o gesto antinormativo. Nada hay menos ingenuo, nada hay más intencionado, que la elección del libro a criticar. Si se quiere hacer crítica de la crítica de manera seria, se debe partir de los criterios que tiene el crítico para elegir los libros.

En segundo lugar, desplazar el androcentrismo y la heteronorma. La hegemonía crítico-literaria, tanto en prensa como en internet, ha estado históricamente y de manera abrumadora en manos de figuras masculinas $\mathrm{y}$, en concordancia con esto, la literatura de mujeres ha ocupado un lugar marginal en cuanto a legitimación en la historia literaria chilena. La ampliación a la diversidad, me refiero con esto a escrituras de minorías como mujeres, 
homosexuales, sujetos pertenecientes a pueblos originarios, implica la ampliación del canon y, por sobre todo, la visibilización de la diferencia.

En tercer lugar, el reduccionismo que experimentan los géneros literarios. La narrativa se constituye hoy en el género hegemonizador dentro de las producciones literarias. La poesía, el género que más se publica en Chile, es, por otra parte, un territorio ignorado por la crítica literaria, donde prolifera la reseña, la crítica por encargo y, en lo medular, la indiferencia. Las razones que motivan esta condición de desequilibrio entre los géneros, se deben a una norma impuesta por el mercado, ya que es el género que menos se vende. Aunque también habría que profundizar respecto a la relación entre discursividades y retóricas. Se puede decir, a partir de la canción popular por ejemplo, que no es la lírica lo que está en retirada, sino campos discursivos poco maleables o reducibles a expresiones más simples. Así desde la poesía, la narrativa y otras expresiones híbridas o difícilmente clasificables, surgen territorios complejos, de retóricas opacas y resistentes a su mutación en mera información. Evidentemente estas opacidades no tienen, por lo general, cabida en la crítica literaria en prensa.

De lo anterior, se desprende un cuarto punto, a saber: ¿cuál es el rol social que juega la crítica literaria en prensa? Sobre todo considerando que la desigualdad es la marca original de la sociedad chilena. Por lo pronto, creo que una crítica fundada única y exclusivamente en el interior del lenguaje de las elites o de lo que las elites han decidido que debe ser el lenguaje adecuado para hablarle a la gran masa, solo puede ser reproductora del orden social. La politicidad, que debe ser siempre el intento por lograr una nueva repartición o un nuevo ordenamiento social, queda caducada tanto en la retórica especializada de las elites intelectuales (que remarcan la diferencia y refuerzan la distancia) como en el vacío lenguaje demagógico de buena parte de los medios de comunicación de masas. Se vuelve necesario, así, generar una producción crítica que escape de esos dos extremos igualmente reproductores del orden establecido, reflexionando sobre el lenguaje utilizado por el letrado en los medios de comunicación masivos. Es cierto que antes de aquello debiéramos preguntarnos si al intelectual o al letrado 
le interesará aún, dialogar con la comunidad a través de los medios de comunicación masivos ¿o le interesará, más bien, apoyar o defender a los miembros de su tribu? Me refiero específicamente al o la intelectual crítico, no al representante de los intereses de las elites, al orgánico reproductor de la hegemonía. La desaparición del intelectual crítico de los medios, es claramente un efecto de las políticas de ocultamiento e invisibilización, de eso no cabe duda, pero habría que preguntarse qué tanto de comodidad existe e incluso cuánto interviene en esta situación el desprecio de la academia hacia la intervención en lo masivo.

Se vuelve necesario así, situar nuestras lecturas y reinstalar la ética, la autonomía y la independencia del trabajo cultural en lo que podemos denominar uso público de la razón. La desaparición del uso público de la razón solo deja lugar a los poderes fácticos y su lenguaje tecnócrata donde solo tendrá lugar el crítico obsecuente y su discurso afirmatorio doblemente direccionado: hacia sí y hacia la obra. Ambas direccionalidades generadas por el crítico, al validar ya sea la obra, al autor, a la editorial, al propio sujeto crítico, aseguran el orden de las cosas y, por ende, la consolidación de las elites como zonas intocables.

La crisis que vive la crítica literaria y nuestra literatura, es solo parte de la catástrofe cultural que implica la mercantilización de la realidad en su conjunto. A lo anterior, puedo agregar, la negación de la diferencia que atrapa a nuestra sociedad, que espera reconciliarse a partir de la negación de las disonancias, eludiendo la diversidad discursiva, eliminando la disidencia, la problematización de la representación hegemónica de la realidad. Si la crítica literaria renuncia a criticar el orden de las cosas, se habrá logrado, definitivamente, silenciar a la propia literatura, que no es más ni menos que la crítica al orden de las cosas. Asistimos a una privatización del pensamiento crítico $\mathrm{y}$, por ende, a la neutralización de las subjetividades; es por ello que sostengo la urgencia de reivindicar la crítica desde el minoritario territorio de la subjetividad como un acto de resistencia cultural. 


\section{Bibliografía}

Espinosa, Patricia. "Dos aproximaciones a la crítica literaria". Revista Ojo en tinta, Octubre 21, 2013. http://www.ojoentinta.com/2013/dosaproximaciones-a- la-critica- literaria/ . 18 de enero 2016.

Peller, Mariela. "Judith Butler y Ernesto Laclau: debates sobre la subjetividad, el psicoanálisis y la política". Sexualidad, Salud y Sociedad N ${ }^{\circ}$ 7, Rio de Janeiro Abril, 2011. http//www.scielo.br/pdf/sess/n7/a03n7.pdf. 18 de enero 2016.

Rancière, Jacques. Sobre políticas estéticas. Barcelona: Universidad Autónoma de Barcelona, 2005. 